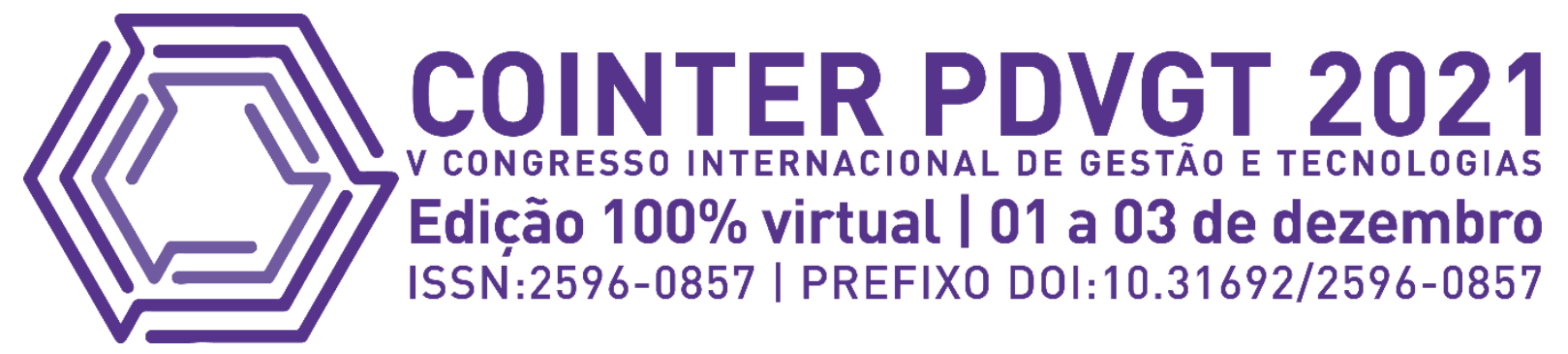

\title{
A EDUCAÇÃO EMPREENDEDORA COMO FOMENTADORA DE SOLUÇÕES: UM ESTUDOS COM OS ALUNOS DE ELETROTÉCNICA E ELETRÔNICA DO IFPE - CAMPUS RECIFE.
}

\section{LA EDUCACIÓN EMPRENDEDORA COMO SOLUCIÓN FOMENTADORA: ESTUDIO CON ESTUDIANTES DE ELECTROTÉCNICA Y ELECTRÓNICA DE IFPE - CAMPUS RECIFE.}

\section{ENTREPRENEURIAL EDUCATION AS A SOLUTION FOSTER: A STUDY WITH ELECTROTECHNICS AND ELECTRONICS STUDENTS AT IFPE - CAMPUS RECIFE.}

\author{
Apresentação: Comunicação Oral \\ Yasmim Nascimento Barbosa ${ }^{1}$; Renata Cristine de Sá Pedrosa Dantas ${ }^{2}$
}

DOI:

\begin{abstract}
RESUMO
Com o passar dos anos o mundo mudou, revoluções, inovações e novas adaptações estão sendo criadas e desta forma o mercado de trabalho vêm se adaptando a este novo modelo de sociedade, sendo assim, a procura de pessoas qualificadas tornou- se cada vez mais recorrente nas empresas. A educação empreendedora como conhecimento que está mais além do que gerenciamento e administração de empresas, se torna um aprendizado que irá formar estudantes como pessoas capazes de tomar decisões e serem capazes de se desenvolver independente de onde estejam. Em um contexto pandêmico, onde crises econômicas e sociais se instalam no mundo, o desemprego aumenta disparadamente e o empreendedorismo se torna uma saída para a população, mas como realizar este tipo de atividade sem um conhecimento básico? Esta pesquisa tem por objetivo levantar dados e entender como a educação empreendedora é tratada nas salas de aula, de forma específica no Instituto Federal de Educação, Ciência e Tecnologia de Pernambuco, com os estudantes dos cursos de Eletrotécnica e Eletrônica. De forma específica, busca-se levantar dados que dizem como este ensino influencia na vida acadêmica desses estudantes, como ela é vista e quais soluções são vistas utilizando o aprendizado da educação empreendedora, e quais soluções podem emergir no pós-pandemia. Esta pesquisa visa a educação empreendedora enquanto promotora do desenvolvimento pessoal e profissional entre alunos dos cursos de eletrônica e eletrotécnica do IFPE Campus Recife identificando como se dá o incentivo para
\end{abstract}

\footnotetext{
Aluna do Curso Técnico em mecânica, Instituto Federal de Pernambuco - Campus Recife, vnb@discente.ifpe.edu.br

${ }^{2}$ Doutora em Ciência da Computação pelo Centro de Informática/UFPE, Professora do Instituto Federal de Pernambuco - Campus Recife, renatadantas@recife.ifpe.edu.br
} 
formação empreendedora dos estudantes e como isso tem ajudado nessa atual crise da pandemia do covid-19. Concluímos que o conhecimento em educação empreendedora está presente no IFPE e muitos estudantes dos cursos técnicos de eletrônica e eletrotécnica apresentam algumas das diversas habilidades deste ensino. Contudo, nem todos apresentaram conhecimento sobre a importância deste ensino como fomentador de seu desenvolvimento profissional e pessoal, como administradores de sua própria empresa e responsáveis pelo seu ingresso no mercado de trabalho.

Palavras Chaves: Educação Empreendedora, Desenvolvimento Profissional e Pessoal, Inovação.

\title{
RESUMEN
}

Con los años el mundo ha cambiado, se van creando revoluciones, innovaciones y nuevas adaptaciones y así el mercado laboral se ha ido adaptando a este nuevo modelo de sociedad, por lo que la búsqueda de personas cualificadas se ha vuelto cada vez más recurrente en las empresas. La educación emprendedora como conocimiento que va más allá de la mera creación de empresas, se convierte en un aprendizaje que formará a los estudiantes como personas capaces de tomar decisiones y poder desarrollarse sin importar dónde se encuentren. En un contexto pandémico, donde se están produciendo crisis económicas y sociales en el mundo, el desempleo se dispara y el emprendimiento se convierte en una salida para la población, pero ¿cómo realizar este tipo de actividad sin conocimientos básicos? Esta investigación tiene como objetivo recopilar datos y comprender cómo se trata la educación emprendedora en las aulas, específicamente en el Instituto Federal de Educación, Ciencia y Tecnología de Pernambuco, con estudiantes de los cursos de Electrotecnia y Electrónica. En concreto, se busca levantar datos que digan cómo esta enseñanza influye en la vida académica de estos estudiantes, cómo se ve y qué soluciones se ven utilizando el aprendizaje de la educación emprendedora, y qué soluciones pueden surgir en la pospandémica. Esta investigación tiene como objetivo la educación emprendedora como promotora del desarrollo personal y profesional entre los estudiantes de los cursos de electrónica y electrotecnia de IFPE Campus Recife, identificando cómo se da el incentivo a la formación emprendedora de los estudiantes y cómo esto ha ayudado en esta crisis actual de la covid- 19 pandemia. Concluimos que el conocimiento en educación emprendedora está presente en IFPE y muchos estudiantes de los cursos de electrónica y electrotécnica tienen algunas de las diversas habilidades de esta enseñanza. Sin embargo, recalco, no todos eran conscientes de la importancia de esta educación como promotora de su desarrollo profesional y personal, como administradores de su propia empresa y responsables de su entrada al mercado laboral.

Palabras clave: Educación Emprendedora, Desarrollo Profesional y Personal, Innovación.

\begin{abstract}
Over the years the world has changed, revolutions, innovations and new adaptations are being created and thus the labor market has been adapting to this new model of society, so the search for qualified people has become increasingly recurrent in companies . Entrepreneurial education as knowledge that goes beyond just creating companies, becomes an apprenticeship that will form students as people capable of making decisions and being able to develop regardless of where they are. In a pandemic context, where economic and social crises are taking place in the world, unemployment increases skyrocketing and entrepreneurship becomes a way out for the population, but how to carry out this type of activity without basic knowledge? This research aims to gather data and understand how entrepreneurial education is treated in classrooms, specifically at the Federal Institute of Education, Science and Technology of Pernambuco, with students from the Electrotechnics and Electronics courses. specifically, it seeks to raise data that say how this teaching influences the academic life of these students, how it is seen and which solutions are seen using entrepreneurial education learning, and which solutions may emerge in the post-pandemic. This research aims at entrepreneurial education as a promoter of personal and professional development among students of electronics and electrotechnics courses at IFPE Campus Recife, identifying how the incentive for students' entrepreneurial training is given and how this has helped in this current crisis of the covid-19 pandemic . We concluded that knowledge in entrepreneurial education is present at IFPE and many
\end{abstract}


students from the electronics and electrotechnical courses have some of the diverse skills of this teaching. However, I emphasize, not all of them were aware of the importance of this education as a promoter of their professional and personal development, as administrators of their own company and responsible for their entry into the labor market.

Keywords: Entrepreneurial Education, Professional and Personal Development, Innovation.

\section{INTRODUÇÃO}

Dados do Instituto de Geografia e Estatística (IBGE, 2020) divulgaram que a taxa de desemprego no Brasil chegou a 14,2\% em 2020, o que revela que as pessoas estão desempregadas mas isso não necessariamente afirma que elas não estão à procura de emprego ou que desistiram de ingressar no mercado de trabalho e ter sua carteira assinada. Dessa forma, pode-se inferir que os empregos formais estão diminuindo cada vez mais no país, o que leva essas pessoas a verem o empreendedorismo como uma saída, o que torna o cidadão comum capaz de encontrar soluções que transformem a sua realidade.

O IFPE como uma instituição de ensino que forma jovens e adultos qualificados para o mercado de trabalho, possui uma estrutura que possibilita formação de profissionais técnicos com capacidade de empreender como alternativa formal, já que se tem uma alta demanda no mercado de trabalho. Dessa forma, é possível verificar que a educação empreendedora se mostra como alternativa viável e é, também, um papel da promotora de ensino trazer esse conhecimento para que o profissional esteja apto para se desenvolver academicamente e no mercado de trabalho.

A educação empreendedora tem como objetivo desenvolver o empoderamento das pessoas, para que saibam encontrar as soluções corretas para qualquer que seja o problema, pois empreender não é apenas gerenciar negócios ou criar empresas, mas sim saber a partir de habilidades próprias retirar/criar alternativas e usufruir delas em benefício próprio.

Esta pesquisa visa a educação empreendedora enquanto promotora do desenvolvimento pessoal e profissional entre os discentes dos cursos de eletrônica e eletrotécnica, do IFPE - Campus Recife, querendo de forma específica, identificar o incentivo para a formação empreendedora dos estudantes e como isso tem somado neste momento atual de crise, no cenário da pandemia da Covid-19. Assim, tem como objetivo geral identificar como os conteúdos de educação empreendedora podem favorecer os alunos Eletrônica e Eletrotécnica no IFPE, Campus Recife, para o enfrentamento da crise, oriunda da pandemia COVID-19. 


\section{FUNDAMENTAÇÃO TEÓRICA}

Segundo Baggio (2014) o empreendedorismo é a arte de fazer acontecer com criatividade e motivação. Um empreendedor está sempre buscando entender e aprender mais sobre si mesmo. Empreendedores são pessoas criativas, que são capazes de encontrar soluções a partir de seus conhecimentos.

$\mathrm{Na}$ nossa sociedade ainda existem pessoas que acreditam que o empreendedorismo é um dom que se nasce com ele, mas a criatividade e as habilidades empreendedoras podem sim ser incorporadas nas metodologias de ensino e as instituições educacionais podem encorajar especialidades relacionadas com inovação (BANERJI et al., 2010). Alguns sistemas são responsáveis por formar estudantes apenas para trabalhar, o que gera conflitos e resistências a partir do ensino da educação empreendedora como preparadora e qualificadora para o mercado de trabalho. Segundo Filion (2000) o importante no ensino do empreendedorismo não é o que se aprende, mas sim como se aprende.

Os princípios pedagógicos do IFPE têm como um dos objetivos formar um profissional flexível frente a novas condições de ocupação no mundo do trabalho, através de um ambiente interdisciplinar (IFPE, 2012). A principal atividade de um empreendedor é conhecer o mercado, identificar nele oportunidades, organizar seus objetivos, projetar, estruturar e dar vida a essa organização.

Dornelas (2001) diz que as habilidades de um empreendedor podem ser divididas em três áreas: técnicas, gerenciais e características pessoais. As técnicas são as práticas do conhecimento para sua atuação, o que envolve saber escrever, ouvir, liderar, ter uma boa oratória, ser organizado e captar informações. A capacidade de gerenciar inclui acompanhar os processos de uma empresa ou negócio o que nos leva a outras áreas de conhecimento. Por fim, as características pessoais são a formação profissional do empreendedor sendo o mesmo capaz de tomar decisões, assumir riscos e liderar sua organização.

Para Filion (2000), um empreendedor é uma pessoa que imagina, desenvolve e realiza visões além de ser criativo e ter a capacidade de estabelecer a atingir seus objetivos, mas sempre mantendo um nível de consciência adaptado ao ambiente que se encontra, detectando oportunidades de negócio.

Dessa forma, o empreendedor é aquele capaz de administrar, identificar e encontrar soluções para seu negócio, sendo um subproduto destas qualidades as habilidades de 
liderança, trabalho em equipe, marketing, oratória e etc. A partir destas características podemos concluir que empreendedor é aquele que sabe utilizar suas qualificações em benefício próprio sendo capaz de crescer no mercado de trabalho e até mesmo criar sua própria empresa.

Muitos educadores estão a ver este atual momento de crise como uma oportunidade para reinventar e adaptar os métodos de ensino do empreendedorismo para a tecnologia da informação e comunicação, ou seja, adaptá-la ao nosso "novo normal", onde tem-se o constante avanço dessa tecnologia e dos seus dependentes.

\section{METODOLOGIA}

Foi realizada uma pesquisa, que para Fleury e Werlang (2017) pesquisas têm como objetivo elaborar diagnósticos, identificar e buscar soluções para problemas presentes nas atividades das instituições, organizações, grupos ou atores sociais. A mesma tendo sua natureza qualitativa, que segundo Denzin e Lincoln (2006), uma pesquisa qualitativa envolve abordagem interpretativa do mundo, isso significa que seus pesquisadores estudam coisas em seus cenários naturais, buscando compreender os fenômenos em termos dos significados que as pessoas conferem a eles.

Orientou-se a partir de um cronograma de atividades onde teve seu início em agosto de 2020, no primeiro momento da pesquisa a revisão da literatura e a análise de documentos foi o marco, através de artigos procurou-se entender o contexto, pensamentos e opiniões sobre como a educação empreendedora é tratada atualmente de um modo geral, escritores e outros pesquisadores que trazem uma base científica sobre o tema. Após essas análises deu-se início a identificação do público-alvo e campo de pesquisa

O campo de pesquisa é o campus Recife do Instituto Federal de Pernambuco. Os sujeitos de pesquisa serão docentes e discentes dos cursos de Eletrônica e Eletrotécnica do IFPE, Campus Recife.

No segundo momento a coleta e categorização dos dados, após a análise teórica deu-se início a prática, com aplicação de questionários abertos para docentes e discentes, que segundo Gil (1946) é um conjunto de questões respondidas pelos pesquisados. Onde foram aplicados através do Google Formulários, dando início no dia 17/05/2021 e encerrando no dia 10/07/2021.

A partir das respostas a estes questionários chegou-se à conclusão da pesquisa, onde 
todos os dados foram organizados e tabulados em Software Excel@C, com a utilização de planilhas para melhor entendimento do levantamento dos dados com precisão.

Por fim, os dados foram apresentados, discutidos e analisados para fechamento da pesquisa e atendimento dos objetivos.

\section{RESULTADOS E DISCUSSÃO}

Os dados apresentados abaixo foram obtidos a partir de um questionário aplicado aos discentes das modalidades integrado e subsequente dos cursos de eletrônica e eletrotécnica, e da mesma forma aos docentes. Sendo assim, a pesquisa apresenta uma participação total de 37 estudantes e 11 professores e servidores. Em virtude da pandemia de COVID-19 e da restrição de contatos pessoais, não foi possível ampliar o número de respondentes, embora se tenha ampliado o prazo de aplicação em quase dois meses.

O Instituto Federal de Pernambuco - Campus Recife, tendo atualmente 456 estudantes matriculados no Curso Técnico em Eletrônica, sendo 310 estudantes da modalidade integrado e 146 da modalidade subsequente, e 554 estudantes matriculados no Curso Técnico em Eletrotécnica, destes 382 são da modalidade integrado e 172 na modalidade subsequente. De acordo com dados do próprio campus do IFPE, no Curso Técnico em Eletrônica, os estudantes do ensino integrado representam aproximadamente $68 \%$ do total de estudantes, no Curso Técnico em Eletrotécnica esse número é bem próximo, representando em torno de 69\% do total de estudantes do curso (IFPE, 2020b).

\subsection{Perfil dos Respondentes}

Para avaliar o perfil dos estudantes e professores e conhecer de forma mais específica o público participante desta pesquisa, foram levantadas questões como: sexo, etnia, faixa etária e, renda familiar, como podemos observar nas figuras 1, 2, 3 e 4 citadas abaixo.

A Figura 1 apresenta o sexo dos respondentes, dos 37 estudantes participantes apenas $25 \%$ são mulheres e $75 \%$ homens, como apresentado no gráfico abaixo, e dos Professores $100 \%$ são homens, isto se dá porque ambos os cursos são das engenharias, com foco em ciências naturais, que de acordo com dados de fácil acesso, encontrados na internet e noticíados cotidianamente, e infelizmente realidades vividas atualmente, são os cursos em que o número de mulheres é menor que o de homens.

De acordo com Rodrigues e De Carvalho (2019), a quantidade de mulheres 
matriculadas em cursos de graduação é maior que a quantidade de homens, contudo isso não se aplica aos cursos de Eletrônica e Eletrotécnica.

Figura 01: Orientação sexual dos estudantes de eletrônica e eletrotécnica do IFPE Campus-Recife.

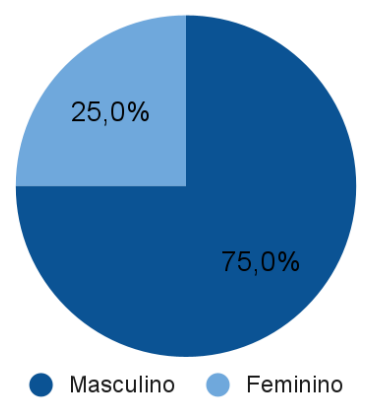

Fonte: Própria (2021).
Figura 02: Renda Familiar dos estudantes de eletrônica e eletrotécnica do IFPE Campus-Recife.

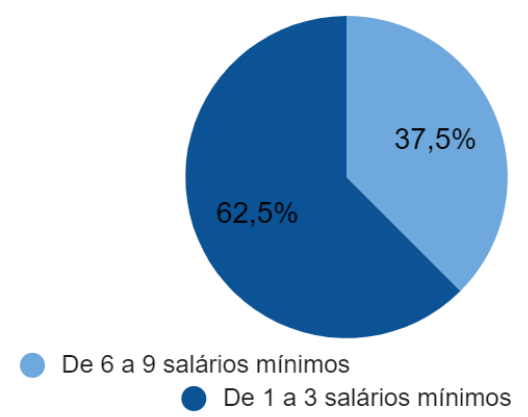

Fonte: Própria (2021).

Na Figura 2, observa-se que dos estudantes respondentes $62,5 \%$ possuem renda máxima de até 3 salários mínimos, o que entende-se como estudantes de baixa ou média renda, isto se dá pelos acessos que as classes mais baixas vêm conquistando com o passar dos anos. Notou-se que nos últimos anos o acesso de estudantes oriundos de escolas públicas tem aumentado nas universidades brasileiras, ocorrido pelo crescimento de vagas criadas para estes estudantes por algumas iniciativas governamentais (MORCHE; NEVES, 2011).

Figura 03: Raça dos estudantes de eletrônica e eletrotécnica do IFPE Campus-Recife.

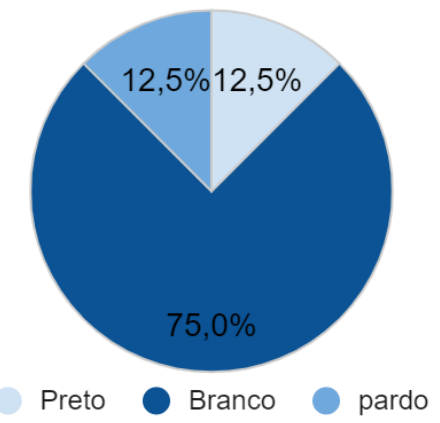

Fonte: Própria (2021).
Figura 04: Faixa Etária de idade dos estudantes de eletrônica e eletrotécnica do IFPE Campus-Recife.

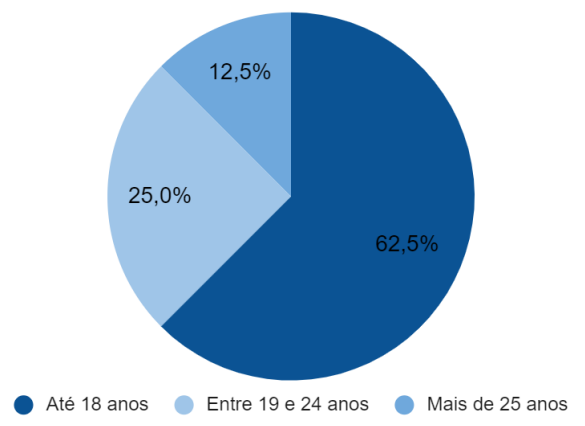

Fonte: Própria (2021).

Nas Figuras 3 e 4, descrevem-se as raças e faixa etária de idade dos estudantes, onde uma maioria é branca e menor de 18 anos, e estes números representam respectivamente $75 \%$ do total dos respondentes do quesito raça e $62,5 \%$ dos estudantes, dessa forma entende-se que a maior parte deles são jovens adolescentes.

\subsection{Auto-avaliação Empreendedora}

No questionário foram apresentadas questões que buscam entender o perfil empreendedor dos professores e estudantes, como serão mostradas abaixo. 
Figura 05: Características Empreendedoras dos discentes de eletrônica e eletrotécnica do IFPE Campus-Recife.

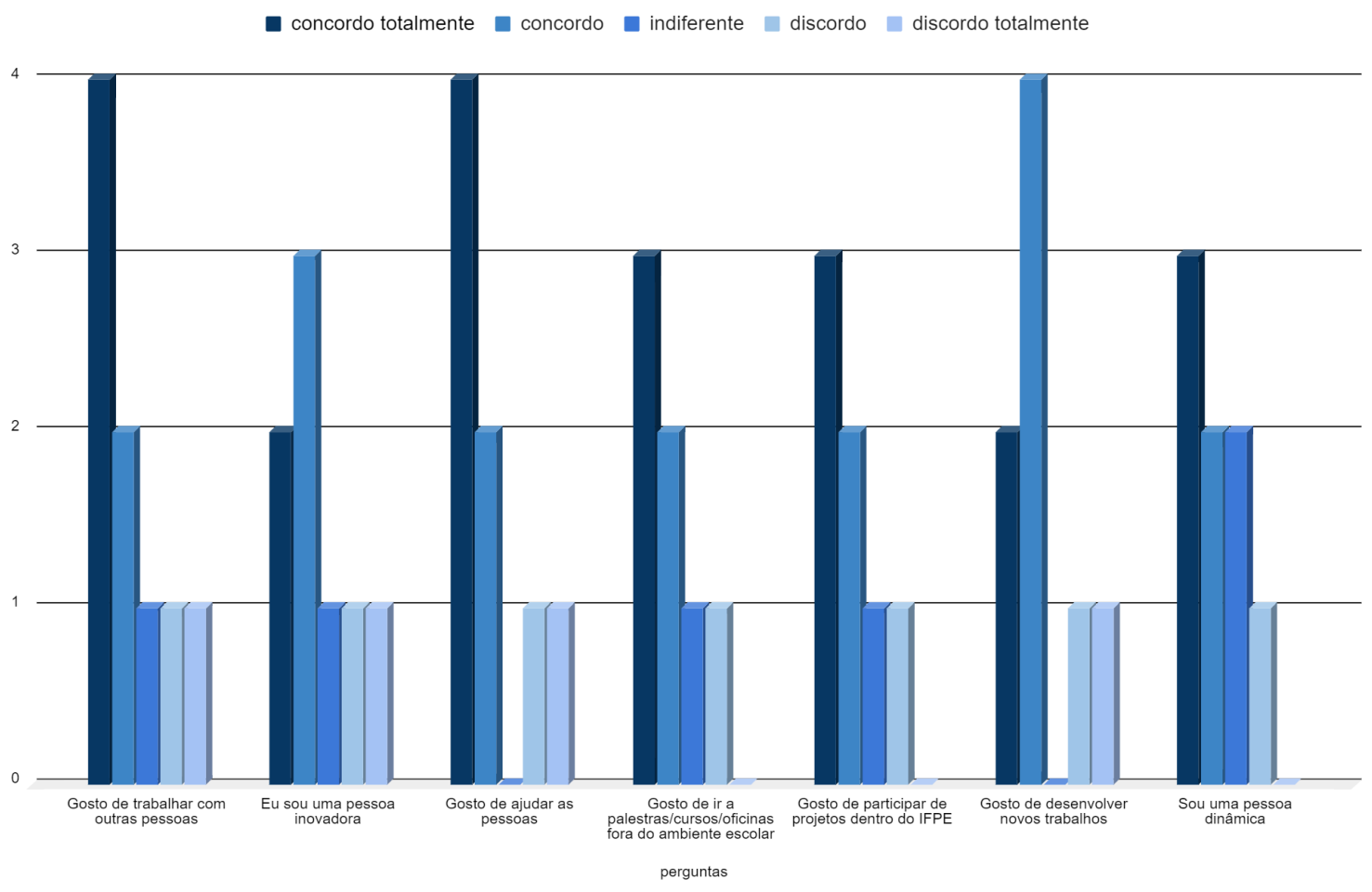

Fonte: Própria (2021).

Figura 06: Características Empreendedoras dos Docentes de eletrônica e eletrotécnica do IFPE Campus-Recife. Característica Empreendedora dos Docentes

- Concordo totalmente concordo $\square$ indiferente $\quad$ discordo discordo totalmente

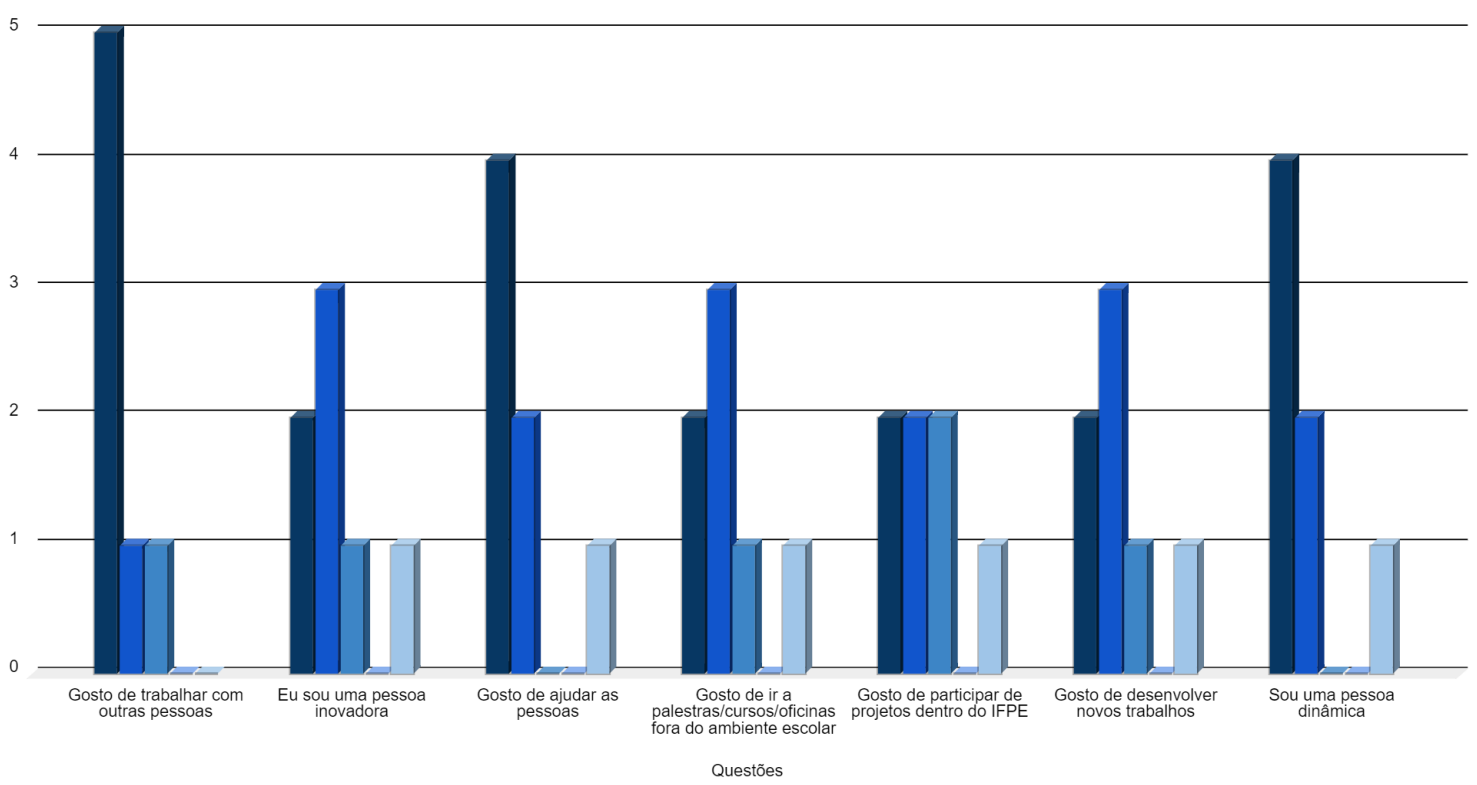

Fonte: Própria (2021). 
Com as respostas é possível observar que os discentes identificam neles mesmo estas habilidades como empreendedores, já nos docentes observa-se uma certa desmotivação, seja por dificuldades que enfrentam com relação a material, estudantes ou outros problemas com a instituição. “O IFPE é pouco flexível.”, "Estamos muito distantes dos clientes que absorvem os nossos produtos.", "Não há uma premissa institucionalizada nesse sentido.” Todas as frases citadas foram ditas por alguns Professores do IFPE que participaram da pesquisa.

\subsection{Protagonismo Estudantil}

Figura 07: Atuação dos discentes de eletrônica e eletrotécnica do IFPE Campus-Recife.

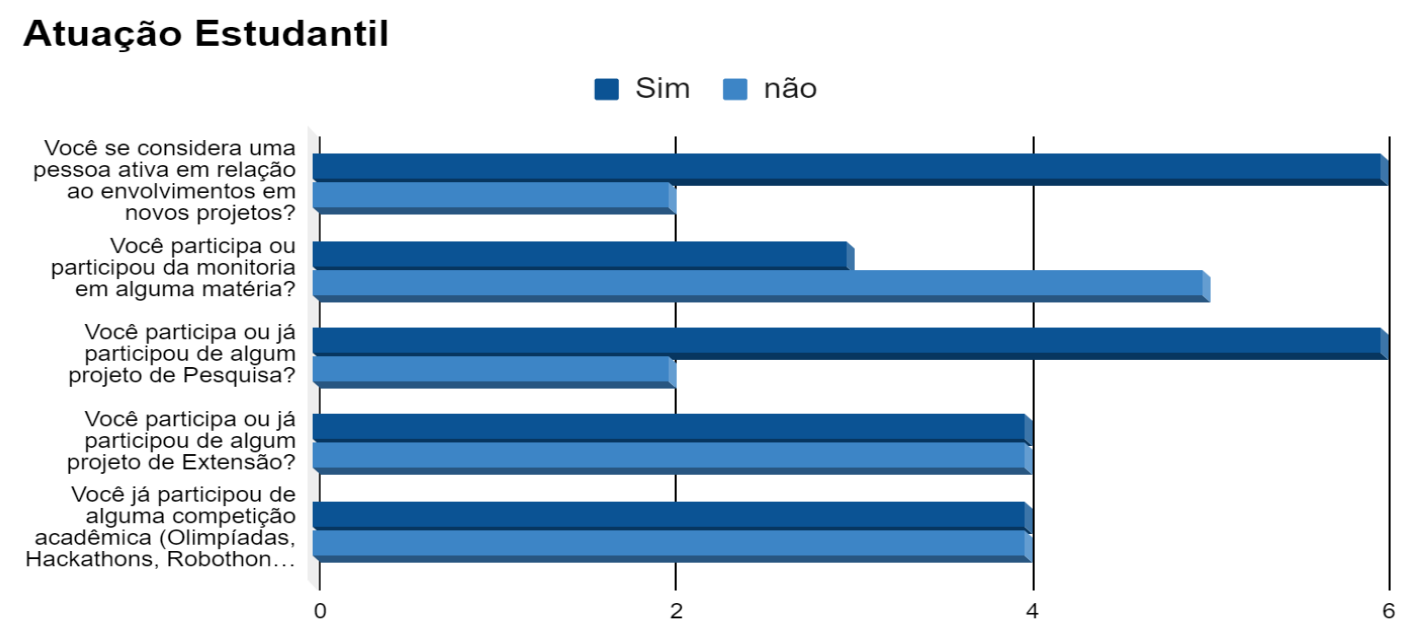

Fonte: Própria (2021).

Como mostra a Figura 07, é notável que os estudantes possuem interesse em atividades extracurriculares que são cruciais para o protagonismo, onde ocorre o embelezamento do currículo, prática e qualificação acadêmica.

Figura 08: Porcentagem dos professores de eletrônica e eletrotécnica do IFPE Campus-Recife que conhecem o que é protagonismo estudantil. 


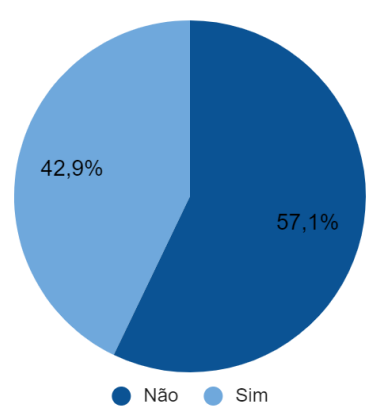

Fonte: Própria (2021).

Seguindo a mesma linha, na Figura 8 observa-se que paralelamente os Docentes não sabem do que se trata este protagonismo, mas ambos afirmam que o IFPE proporciona eventos deste porte para incentivar os estudantes, se reconhecendo também como uma instituição federal de incentivo à pesquisa e qualificação para o mercado de trabalho, como mostra o gráfico abaixo.

Figura 09: Sobre a estimulação do protagonismo estudantil do IFPE Campus-Recife.

\section{O IFPE estimula o protagonismo estudantil?}

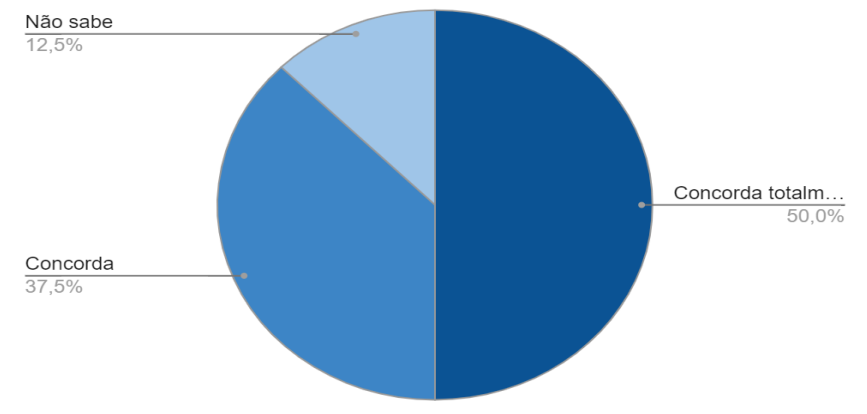

Fonte: Própria (2021).

Dessa forma, como mostra a Figura 09, observamos a atuação dos docentes na pesquisa e contribuição em eventos e congressos científicos com trocas de conhecimento, como orientadores de pesquisas desenvolvidas por discentes. O gráfico abaixo nos afirma que os professores possuem projetos desenvolvidos por eles mesmos, mas como orientadores e organizadores de eventos este número recebe uma queda quando comparado com projetos desenvolvidos pelos mesmos.

Figura 10: Atuação dos docentes de eletrônica e eletrotécnica do IFPE Campus-Recife com relação à pesquisa. 


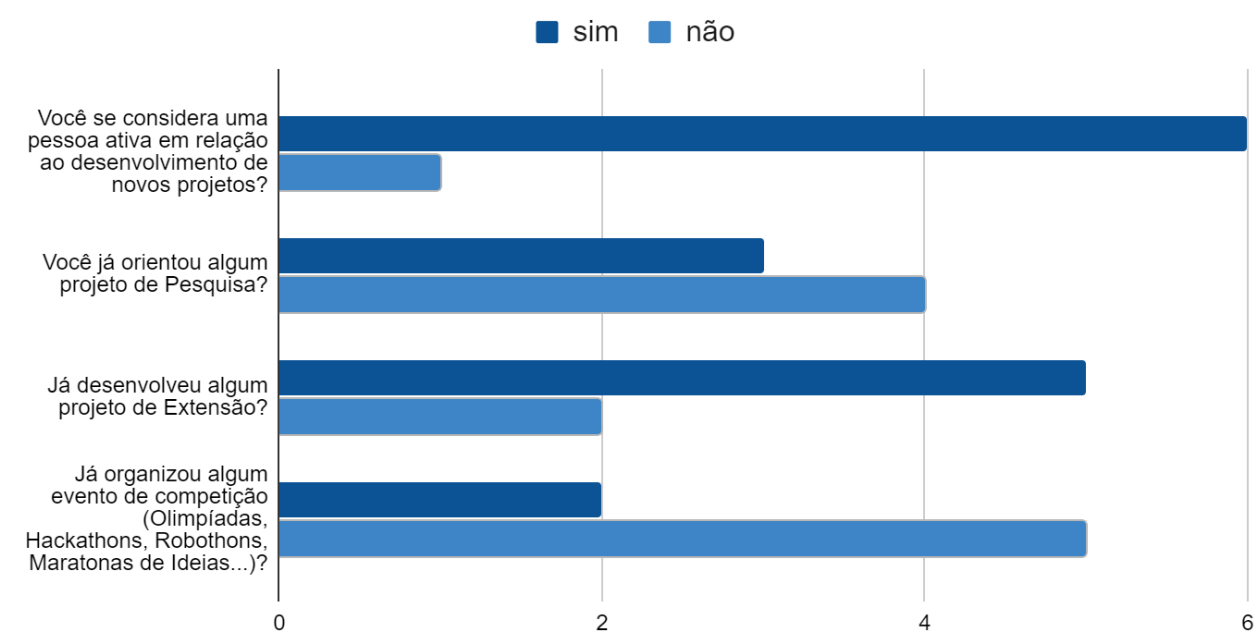

Fonte: Própria (2021).

O gráfico na Figura 10 acima, nos afirma que os professores possuem projetos desenvolvidos por eles mesmos, mas como orientadores e organizadores de eventos este número recebe uma queda quando comparado com projetos desenvolvidos pelos mesmos.

\subsection{Educação Empreendedora e Sua Importância}

Como foco, esta pesquisa busca entender como em uma instituição federal a educação empreendedora é retratada pelos Professores, e como os estudantes entendem esse ensino e se ambas as partes têm ciência de sua importância para seu desenvolvimento pessoal e profissional. Assim, a partir da pesquisa em campo trarei a análise dos dados obtidos.

Figura 11: Você sabe o que é Educação Empreendedora? Gráfico dos Discentes

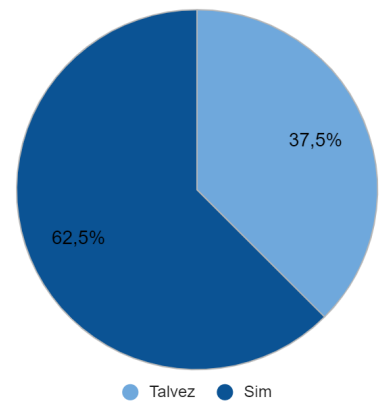

Figura 12: Você sabe o que é Educação Empreendedora? Gráfico dos Docentes

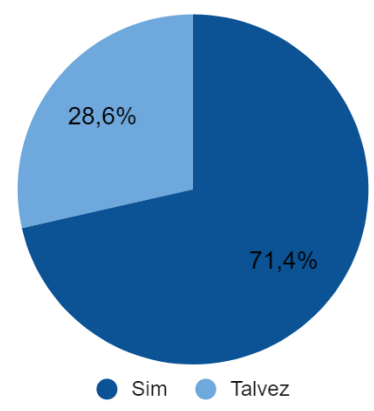

Fonte: Própria (2021).

Os números apresentam positividade ao afirmarem que boa parte dos entrevistados 
sabem o que é a educação empreendedora, mas nos gráficos abaixo será exposto se sabem a importância dessa educação.

Figura 13: Sabem qual a importância da Educação Empreendedora? Discentes de Eletrônica e Eletrotécnica do IFPE - Recife.

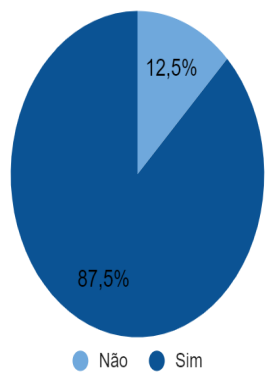

Figura 14: Já pensou em empreender, desenvolver um produto ou serviço? Discentes de Eletrônica e Eletrotécnica do IFPE - Recife.

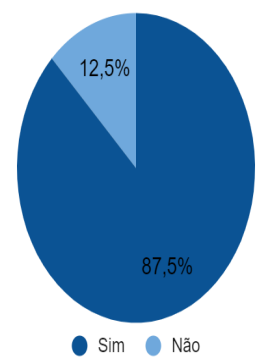

Figura 15: Já participou de disciplinas que precisam do conhecimento sobre empreendedorismo? Discentes de Eletrônica e Eletrotécnica

Fonte: Própria (2021). do IFPE - Recife.

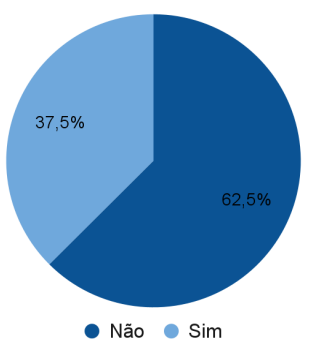

A partir destas respostas é possível perceber que os estudantes ficam entusiasmados com a ideia de ser um empreendedor (Figura 14), e tomam conhecimento do que é a educação empreendedora (Figura 13), sendo os mesmos protagonistas de suas histórias, traçando ideias e perspectivas a partir do protagonismo estudantil para estarem preparados para o futuro e seus desafios, dessa forma a ideia da educação empreendedora se torna clara com relação aos estudantes que alegam, em sua maioria, apenas que este conhecimento não se aplicou em outras disciplinas, como mostra a Figura 15.

Figura 16: Quais atividades podem influenciar no desenvolvimento acadêmico? Discentes de Eletrônica e Eletrotécnica do IFPE - Recife. 


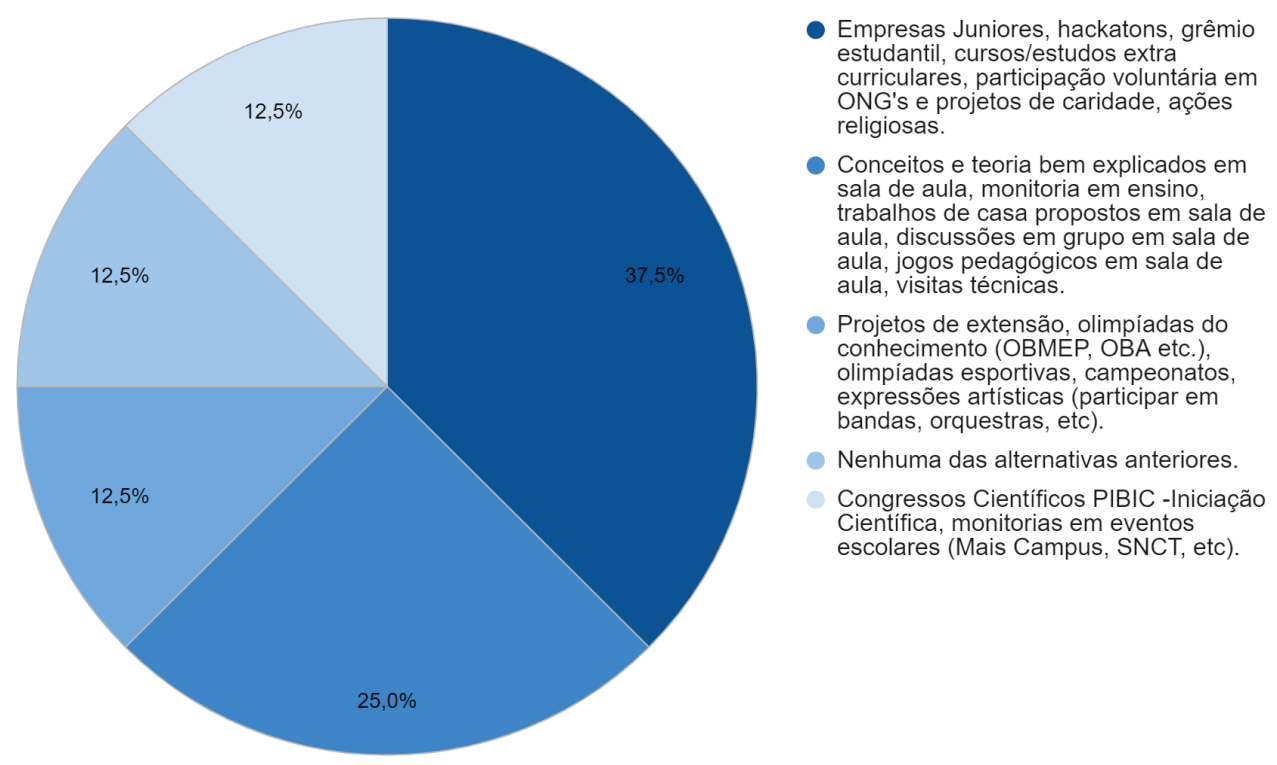

Fonte: Própria (2021).

Eventos sobre criação de empresas, como startups são atualmente um dos mais procurados pelos jovens, pois como sabemos a procura por empregos autônomos vem se tornando cada vez mais recorrente, tanto por questões de crises econômicas e sociais como pela ideia de ser você mesmo seu patrão e dono de um negócio próprio, desta forma os estudantes têm mostrado mais interesse a este tipos de evento, como mostra a Figura 16.

Figura 17: Com que frequência os Professores comentam sobre atividades que auxiliam no desenvolvimento acadêmico? Discentes de Eletrônica e Eletrotécnica do IFPE - Recife.

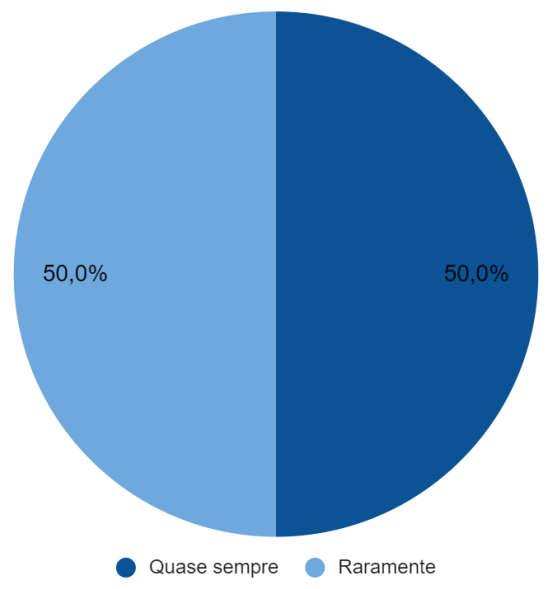

Fonte: Própria (2021). 
Porém, a Figura 17 mostra que em sala de aula a divulgação destes eventos vem da dependência do professor, alguns comentam e outros não.

Figura 18: Já teve a experiência de ver algum estudante que colocou este ensino em prática e obteve sucesso? Docentes de Eletrônica e

Eletrotécnica do IFPE - Recife.
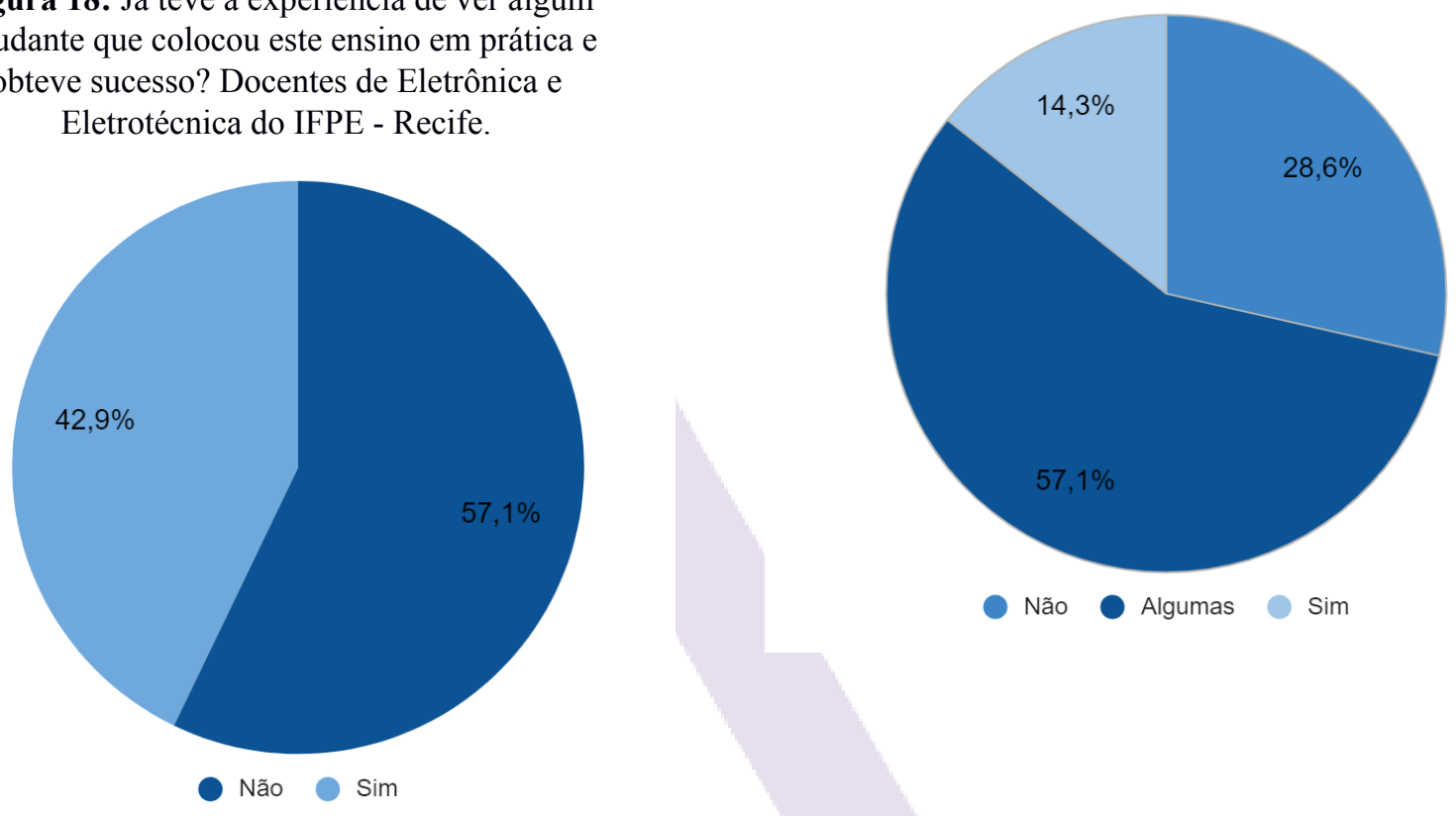

Figura 19: Considera que muitas disciplinas envolvem o ensino de Educação Empreendedora? Docentes de Eletrônica e Eletrotécnica do IFPE Recife.

Fonte: Própria (2021).

Sobre a prática deste ensino, como muitos docentes não possuem conhecimento sobre a educação empreendedora (Figura 12), então podemos considerar que uma boa parte dos entrevistados afirmam que a prática deste ensino, quando bem aplicada e compreendida traz sucesso para o indivíduo, como mostra a Figura 18 e alguns também consideram que este ensino se aplica a outras disciplinas (Figura 19).

Por fim, concluímos que o conhecimento em educação empreendedora está presente no IFPE e muitos estudantes dos cursos técnicos de eletrônica e eletrotécnica apresentam algumas das diversas habilidades deste ensino. Contudo ressalto, nem todos apresentaram conhecimento sobre a importância deste ensino como fomentador de seu desenvolvimento profissional e pessoal, como administradores de sua própria empresa e responsáveis pelo seu ingresso no mercado de trabalho

\section{CONCLUSÕES}


A educação empreendedora possui extrema importância atualmente na sociedade, de forma específica quando se trata de um contexto pandêmico, onde crises sociais e econômicas se instalam no país, dessa forma este ensino como formador de estudantes e profissionais capazes de se desenvolver no mercado de trabalho e desenvolver até mesmo o seu próprio empreendimento. Com relação a este ensino no Instituto Federal de Pernambuco CampusRecife e os cursos aqui selecionados para realização desta pesquisa, reconhecendo sua importância, é possível perceber que a instituição se empenha em relação ao crescimento deste ensino com os estudantes.

Nos cursos estudados, esta disciplina aparece como Empreendedorismo, na qual são abordadas noções do empreendedorismo nas identificações de habilidades, competências e oportunidades de negócios. Uma grande parte dos estudantes tem interesse em aprender ou já aplicam a EE (Educação Empreendedora) em suas decisões, porém os mesmo afirmar que uma parte não tem conhecimento desta disciplina em seus cursos e outras afirmam que já cursaram tiveram uma boa experiência e a partir deste disciplina tomaram a iniciativa de começar a empreender.

Outrora, Professores não afirmam o mesmo pensamento, os mesmo declaram que não possuem muito contato com a educação empreendedora mas se interessam por ela, entendem a importância da mesma e sua aplicação com os estudantes e com eles mesmos.

Por fim, com base nas discussões e afirmações trazidas aqui em conclusão o IFPECampus Recife poderia trazer a EE para fora da sala de aula e englobar os Professores como um todo neste processo junto com os estudantes, trazendo assim a pesquisa, em seus eventos um espaço para que haja uma discussão sobre este ensino e dessa forma todos Docentes e Discentes tenham uma boa experiência e tomem conhecimento da importância e fundamentalidade que esta educação tem para todos, tendo em vista o interesse e as habilidades por parte dos Professores e Estudantes, sendo possível também que os mesmos enxerguem a EE em outras disciplinas, seja para criação de uma solução ou trabalho em equipe.

As limitações da pesquisa se apresentaram na obtenção de respostas ao questionário, dado que, em momento de afastamento social e onde os discentes e docentes tem acumulado atividades, foi muito difícil a coleta de dados. O que gera oportunidades para ampliação dos respondentes na volta do ensino presencial. 


\section{REFERÊNCIAS}

BAGGIO, Adelar Francisco; BAGGIO, Daniel Knebel. Empreendedorismo: Conceitos e definições. Revista de Empreendedorismo, Inovação e Tecnologia, Passo Fundo, v. 1, n. 1, p. 25-38, jan. 2015. Disponível em: https://seer.imed.edu.br/index.php/revistasi/article/view/612. Acesso em: 18 jun. 2021. DOI https://doi.org/10.18256/2359-3539/reit-imed.v1n1p25-38.

BANERJI, Arup; CUNNINGHAM, Wendy; FISZBEIN, Ariel; KING, Elizabeth; PATRINOS, Harry; Robalino, David; TAN, Jee-Peng. Stepping Up Skills for More Jobs and Higher Productivity. Washington, DC: Banco Mundial, 2010. Disponível em: https://openknowledge.worldbank.org/handle/10986/27892. Acesso em: 20 jun. 2021.

DOLABELA, Fernando. Oficina do empreendedor. Rio de Janeiro: Sextante, 2008.

DORNELAS, José Carlos Assis. Empreendedorismo: transformando idéias em negócios. Rio de Janeiro: Campus, 2001.

DRUCKER, Peter. Inovação e Espírito Empreendedor. São Paulo: Pioneira, 1986.

FILION, Louis Jacques. Empreendedorismo e gerenciamento: processos distintos, porém complementares. Revista de Administração de Empresas, v. 40, n. 3, p. 8-17, 2000.

FILION, Louis Jacques. Empreendedorismo e Gerenciamento: Processos Distintos, Porém Complementares. RAE-Revista de Administração de Empresas, São Paulo, v. 40, n. 3, p. 8-17, set. 2000. Disponível em: http://www.scielo.br/scielo.php?script=sci_arttext\&pid=S0034-75902000000300013\&lng=pt \&nrm=iso. Acesso em: 19 jun. $2021 . \quad$ DOI http://dx.doi.org/10.1590/S0034-75902000000300013

FLEURY, Maria Tereza Leme; WERLANG, Sergio Ribeiro da Costa. Pesquisa aplicada: conceitos e abordagens. Anuário de Pesquisa GVPesquisa, São Paulo, nov. 2017. Disponível em: http://bibliotecadigital.fgv.br/ojs/index.php/apgvpesquisa/article/view/72796. Acesso em: 17 jun. 2021.

GIL, Antonio Carlos. Como elaborar projetos de pesquisa. 4. ed. São Paulo: Atlas, 2002.

IFPE. Departamento Acadêmico de Controle de Sistemas Eletro-eletrônicos. Plano do Curso Técnico em Eletrotécnica (Integrado do Ensino Médio). Recife, 2014a. Disponível em: https://portal.ifpe.edu.br/campus/recife/cursos/tecnicos/integrados/eletrotecnica/projeto-pedag ogico/ppc-eletrotecnica-integrado-2014-versao-final.pdf. Acesso em: 25 jun. 2021.

IFPE. Projeto Político Pedagógico Institucional - PPPI. Recife, 2012. Disponível em: https://portal.ifpe.edu.br/campus/recife/o-campus/documentos/projeto-politico-pedagogico-do -ifpe/projeto-politico-pedagogico-do-ifpe.pdf. Acesso em: 18 jun. 2021.

MARTINS, Silvana Neumann et al. INTERFACE TEÓRICA ENTRE O PROTAGONISMO E A EDUCAÇÃO EMPREENDEDORA: APROXIMAÇÕES POSSÍVEIS. Educere et Educare, v. 13, n. 27, p. 10-17648/educare. v13i27. 14613, 2018. 
QUEIROZ, Audemir Leuzinger; PARADELA, Celia Lima. EMPREENDEDORISMO, INDÚSTRIA CRIATIVA E ECONOMIA CRIATIVA: UMA EVOLUÇÃO CONCEITUAL. Revista Eletrônica Estácio Papirus, v. 4, n. 2, 2018.

RODRIGUES, Jannyny de Oliveira Fogaça; DE CARVALHO, Sheyse Martins.

Evasão Feminina no Curso de Licenciatura em Física da UFT. In: WORKSHOP EM ENSINO DE FÍSICA DO TOCANTINS, 3, 2019. Tocantins. III Workshop em Ensino de Física do Tocantins [...]. Tocantins: UFT, 2019

ROUBICEK, Marcelo. O que diz o primeiro dado de desemprego na pandemia. Disponível em: . Acesso em: maio de 2020.

SEBRAE. Conheça o Programa Nacional de Educação Empreendedora. [S.1], [2019?]. Disponível em: https://cer.sebrae.com.br/programa-nacional-de-educacao-empreendedora/. Acesso em: 10 set. 2020. 